\title{
EFFECTIVENESS AND PERSISTENCE OF SIX INSECTICIDES FOR CONTROL OF LETTUCE APHID ON FIELD LETTUCE IN CANTERBURY, NEW ZEALAND
}

\author{
M.A.W. STUFKENS and A.R. WALLACE \\ Crop \& Food Research, Private Bag 4704, Christchurch, New Zealand \\ Corresponding author: stufkensm@crop.cri.nz.
}

\begin{abstract}
Since its arrival in March 2002, lettuce growers in New Zealand have been struggling to control the lettuce aphid (Nasonovia ribisnigri) using topically applied insecticides. Potter tower tests have shown there is some level of resistance in New Zealand to two insecticides (acephate and methomyl) at the recommended field rate. A field trial was set up to examine the effectiveness and persistence of six insecticides on autumn sown seedling lettuces for control of the lettuce aphid. Acephate and methomyl failed to give complete kill of lettuce aphids, unlike the other four insecticides tested. The synthetic pyrethroid, lambda-cyhalothrin, gave a higher level of protection, having both a longer persistence period than the other insecticides tested and a significantly lower rate of increase in aphid numbers.
\end{abstract}

Keywords: Lettuce aphid, lettuce, insecticides, control, persistence.

\section{INTRODUCTION}

The lettuce aphid has been a major pest of lettuce (Lactuca sativa L.) in New Zealand since its arrival in March 2002 (Stufkens et al. 2002; Stufkens \& Teulon 2003). Most commercial lettuce growers have struggled to control the lettuce aphid with topical insecticide applications during the summer/autumn growing periods. Numerous crops were ploughed in when the number of aphids in the lettuce made them unmarketable, and some growers have stopped growing lettuce as a commercial crop. When the lettuce aphid first appeared, lettuce growers used a number of insecticides to try to control the outbreaks without success, indicating to members of the lettuce industry that insecticide resistance could be present, as it is in Europe (Barber et al. 1999). Potter tower tests were carried out to determine the efficacy of 12 pesticides in New Zealand against the lettuce aphid. The results showed that lettuce aphids in New Zealand have some level of resistance to two insecticides, as both acephate (80.6\%) and methomyl (90.7\%) failed to obtain complete mortality (Workman et al. 2004).

The objective of the work described in this paper was to compare the effectiveness of six insecticides on seedling lettuce in a field trial.

\section{METHODS}

In March 2003, seedling (5 leaf) lettuce (cv. Target) was planted in the field at Harewood, Christchurch. The trial consisted of $1 \mathrm{~m}^{2}$ plots with $1 \mathrm{~m}^{2}$ lettuce buffers between plots and around the perimeter of the trial in a randomised block design. There were 16 transplanted lettuce plants per plot, $250 \mathrm{~mm}$ apart. The trial comprised five replicates of six insecticides and a control (sprayed only with water) (Table 1).

Two of the 16 lettuce plants in each plot were planted in 0.09 litre plastic pots and placed in prepared holes in central positions in each plot with the soil surface of the pot level with the ground surface. These two plants were sampled daily for aphids and predators. Lettuce aphids were applied as described below, when required. Pots made it easy to remove plants from the plot and examine them on a bench using $2.5 \mathrm{x}$ magnification to count the aphids and apply more aphids if necessary. 
Ten lettuce aphids (reared on caged lettuces in the field) were placed in the centre of each of the potted plants three hours before the spray treatments were applied to allow time for the aphids to settle. This also gave them time to move to the centre of the plant, inside the young leaves where they are commonly found. The insecticide and water treatments were applied using a knapsack sprayer at a water rate of 500 litres/ha.

After the initial insecticide application a daily count of live aphids, predators and diseased aphids was recorded from each potted plant. If the number of aphids found on the lettuce was less than five on any given day, 10 more live aphids were added to the plant to simulate continuous aphid pressure after the first spray. All the potted plants were hand watered daily after they had been examined for aphids.

After 11 days, a further insecticide application was made to the same plots, as aphid populations in most treatments had reached a mean of 35-40 live aphids per plant, with all aphid growth stages present, similar to populations on the control plants. No aphids were added after the second spray, subsequent infestation being left to natural immigration of aphids, as was observed after the first spray and in suction trap catches at the time.

After the second spray, two of the other sprayed lettuce plants in each plot, to which no aphids had been added (non-potted), were destructively sampled on three occasions, 2, 4 and 10 days after spray application. The plants had between 15 and 19 leaves, and the numbers of nymphs, winged and wingless aphids on these plants were counted.

\section{TABLE 1: Insecticides and rate for both spray applications.}

\begin{tabular}{lll}
\hline Insecticide $^{1}$ & $\mathrm{~g}$ ai/ha & Rate product/ha \\
\hline Lambda-cyhalothrin (Karate Zeon) & 9 & $36 \mathrm{ml}$ \\
Diazinon (Diazinon 800) & 800 & 1 litre \\
Methomyl (Lannate) & 400 & $2 \mathrm{litres}$ \\
Acephate (Orthene WSG) & 776 & $800 \mathrm{~g}$ \\
Dimethoate (Perfekthion) & 400 & $800 \mathrm{ml}$ \\
Pirimicarb (Pirimor) & 125 & $250 \mathrm{~g}$ \\
Water control & & $500 \mathrm{litres}$ \\
\hline
\end{tabular}

${ }^{1}$ Active ingredient with product trade name in parentheses.

Counts of surviving aphids per potted plant became more variable across blocks and plants within plots as the number of aphids increased. Accordingly, a generalised linear mixed model (GLMM) with Poisson error distribution was used to model the patterns of treatment and time trend in the data, separately for each phase of the experiment (i.e. after each spray application). Daily means for each treatment and their standard errors were estimated from the Poisson GLMMs. These were then used as input to a non-linear weighted regression model for the persistence of each chemical. This model estimated persistence separately for each treatment as an initial 'protection period' during which almost all aphids were killed within one day of placing them on plants, or, after the second spray, were contained to less than one or two per plant. The persistence period was assumed to be followed by a period in which there was a linear increase in the number of live aphids each day, with a separate growth rate ('slope') for each treatment. The last two observations for the water control (after the first spray) and the last four observations for pirimicarb (after the second spray) were omitted from the analysis because aphid populations were no longer increasing. Aphid count data from the three destructive samplings and from the potted plants 10 days after the second spray application were analysed by ANOVA after transformation to $\operatorname{sqrt}(n+0.5)$. The GenStat package (GenStat 2002) was used for all analyses.

\section{RESULTS}

No adverse weather conditions occurred during the experiment to affect aphid survival and all the lettuce plants showed normal growth for that time of year. The potted plants 
had smaller leaves than those planted directly in the soil due to root restriction and disturbance caused by the daily removal of the pot from the ground, different soil moisture conditions, and the constant handling of the plant and manipulation of the leaves that was needed to count the aphids.

Winged and wingless adult aphids of three other aphid species (Macrosiphum euphorbiae, Uroleucon sonchi and Aulacorthum solani) as well as lettuce aphid (wingless adults) were found on some potted plants. As the other species had not been applied to the plants, this indicated that immigration was occurring through aphids flying into the site as well as through wingless aphids walking between lettuce plants.

Aphid predators and fungal diseases had little effect on the aphid population during the first spray period, but did occur during the second spray period, reducing aphid numbers, although this was only observed in plants where more than 9 aphids were present. In two control plants and three acephate-treated plants, there was up to a $50 \%$ reduction in live aphids due to a fungal infection.

\section{First spray application}

The control plants sprayed only with water showed good aphid survival and reproduction, reaching a peak infestation level of about 40 aphids per plant 8 days after the first spray of treated plots (Fig. 1). All the insecticides gave good initial control of the aphids except for methomyl and acephate, the two insecticides that did not give $100 \%$ kill in the Potter tower tests. Plants sprayed with lambda-cyhalothrin were protected for 2 days, but in all other treatments populations were increasing from just one day after spraying.

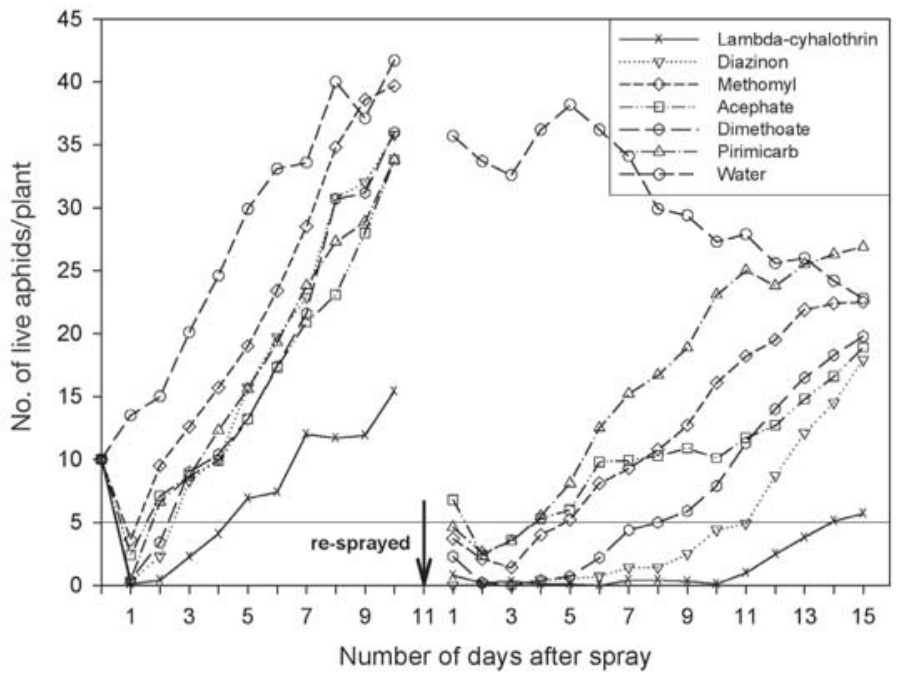

FIGURE 1: Mean number of live aphids on the potted lettuces sampled daily after insecticides were applied on days 0 and 11. Ten aphids were applied to each plant before the first spray and subsequently daily, until day 10, if aphid populations dropped below five per plant. No aphids were added after the second spray on day 11.

Estimates of the persistence parameters (protection periods) and linear growth parameters (slopes) of the model are given in Table 2, together with predictions of the number of days to reach a nominal threshold of five live aphids per plant for each treatment. 
TABLE 2: Parameter estimates and predictions from a non-linear weighted regression model fitted to daily mean numbers of live aphids per plant after the first spray application, for six insecticides and a water-treated control applied in a field experiment on lettuce.

\begin{tabular}{lccccccccc}
\hline & \multicolumn{2}{c}{$\begin{array}{c}\text { Protection period } \\
\text { (days) }\end{array}$} & & \multicolumn{2}{c}{$\begin{array}{c}\text { Slope } \\
\text { (aphids/day) }\end{array}$} & & \multicolumn{2}{c}{$\begin{array}{c}\text { No. days to } \\
\text { five aphids/plant }\end{array}$} \\
\cline { 2 - 3 } Treatment & Mean & SE & & Mean & SE & & Mean & SE \\
\hline Lambda-cyhalothrin & 1.6 & 0.32 & & 1.83 & 0.134 & & 4.38 & 0.189 \\
Diazinon & 1.4 & 0.17 & & 4.24 & 0.178 & & 2.54 & 0.130 \\
Methomyl & 0.0 & 0.18 & & 4.10 & 0.159 & & 1.23 & 0.145 \\
Acephate & 0.2 & 0.21 & & 3.09 & 0.144 & & 1.84 & 0.158 \\
Dimethoate & 1.2 & 0.19 & & 3.94 & 0.178 & & 2.43 & 0.144 \\
Pirimicarb & 0.6 & 0.17 & & 3.59 & 0.146 & & 1.96 & 0.133 \\
Water & -2.3 & 0.42 & & 3.86 & 0.252 & & -0.99 & 0.337 \\
\hline
\end{tabular}

Lambda-cyhalothrin was the only treatment to provide effective ongoing protection; the time to reach five aphids per plant was 4.4 days $(\mathrm{SE}=0.19)$. Corresponding times for diazinon and dimethoate were 2.5 and 2.4 days, respectively, while the other three treatments had times of less than 2 days. The rate of increase in aphid numbers after the persistence period had expired was 1.8 aphids/day $(\mathrm{SE}=0.13)$ for lambda-cyhalothrin, while all other treatments and the water control had increases of between 3.1 and 4.2 aphids/day (Table 2).

Second spray application

Estimates of the persistence parameters (protection periods) and linear growth parameters (slopes) of the model for the period after the second spray are given in Table 3 , together with predictions of the number of days to reach a threshold of five live aphids per plant for each treatment.

Persistence of all the insecticides was greater after the second spray, and the differentiation between treatments was also greater. Lambda-cyhalothrin was again the most persistent, with a value of 10 days $(\mathrm{SE}=0.56)$. Persistence for diazinon was 7.8 days, and for dimethoate 5.1 days; the other three treatments all had persistence of less than 2.1 days. Rates of increase after the end of the persistence period were also significantly different $(\mathrm{P}<0.001)$ between treatments. Lambda-cyhalothrin and acephate had the lowest rates of 1.2 and 1.1 aphids per day. However, the pattern of increase for acephate was the least consistent, and its persistence estimate was the only negative value. Aphid counts in three plots of this treatment were affected by a fungal disease. The other four treatments had rates of increase between 1.9 and 2.5 aphids per day.

TABLE 3: Parameter estimates and predictions from a non-linear weighted regression model fitted to daily mean numbers of live aphids per plant from two days after a second spray application, for six insecticides applied in a field experiment on lettuce.

\begin{tabular}{|c|c|c|c|c|c|c|}
\hline \multirow[b]{2}{*}{ Treatment } & \multicolumn{2}{|c|}{$\begin{array}{l}\text { Protection period } \\
\text { (days) }\end{array}$} & \multicolumn{2}{|c|}{$\begin{array}{c}\text { Slope } \\
\text { (aphids/day) }\end{array}$} & \multicolumn{2}{|c|}{$\begin{array}{c}\text { No. days to } \\
\text { five aphids/plant }\end{array}$} \\
\hline & Mean & $\mathrm{SE}$ & Mean & $\mathrm{SE}$ & Mean & $\mathrm{SE}$ \\
\hline Lambda-cyhalothrin & 10.0 & 0.56 & 1.22 & 0.233 & 14.12 & 0.383 \\
\hline Diazinon & 7.8 & 0.22 & 2.18 & 0.156 & 10.11 & 0.142 \\
\hline Methomyl & 2.1 & 0.25 & 1.92 & 0.086 & 4.72 & 0.177 \\
\hline Acephate & -0.5 & 0.49 & 1.12 & 0.069 & 3.96 & 0.284 \\
\hline Dimethoate & 5.1 & 0.28 & 1.94 & 0.120 & 7.72 & 0.173 \\
\hline Pirimicarb & 1.4 & 0.20 & 2.54 & 0.128 & 3.36 & 0.140 \\
\hline
\end{tabular}


The combination of different persistence values and rates of increase between treatments led to a clear differentiation of treatments in relation to the time taken for estimated mean aphid populations to reach the nominal threshold of five aphids per plant (Table 3). Lambda-cyhalothrin provided this level of protection for 14 days ( $\mathrm{SE}=0.38$ ), diazinon for 10 days $(\mathrm{SE}=0.14)$, dimethoate for 7.7 days $(\mathrm{SE}=0.17)$ and methomyl for 14.7 days $(\mathrm{SE}=0.18)$, while acephate and pirimicarb each provided less than 4 days protection.

By the end of the experiment (15 days after the second spray application) all the treatments except lambda-cyhalothrin had reached mean aphid counts similar to those of the water control (23 live aphids/plant), or were approaching this level (means 18-20 aphids/plant) (Fig. 1).

\section{Destructive sampling}

Mean aphid numbers per plant were much higher in the non-potted (destructively sampled) plants than in the potted plants. For example, 10 days after the second spray application, means ranged from 24 to 36 aphids per plant for the most effective chemicals (lambda-cyhalothrin, diazinon and dimethoate) through to over 100 aphids per plant for the water control and methomyl. In contrast, 10 days after the second spray, the potted plants all had means of less than 30; lambda-cyhalothrin and diazinon treatments were 0.1 and 4.4 mean aphids per plant, respectively.

However, the general pattern of the results was similar for both potted and non-potted plants, with a good correlation $(r=0.72)$ between the treatments for the square root transformed mean aphid counts, 10 days after the second spray (Fig. 2).

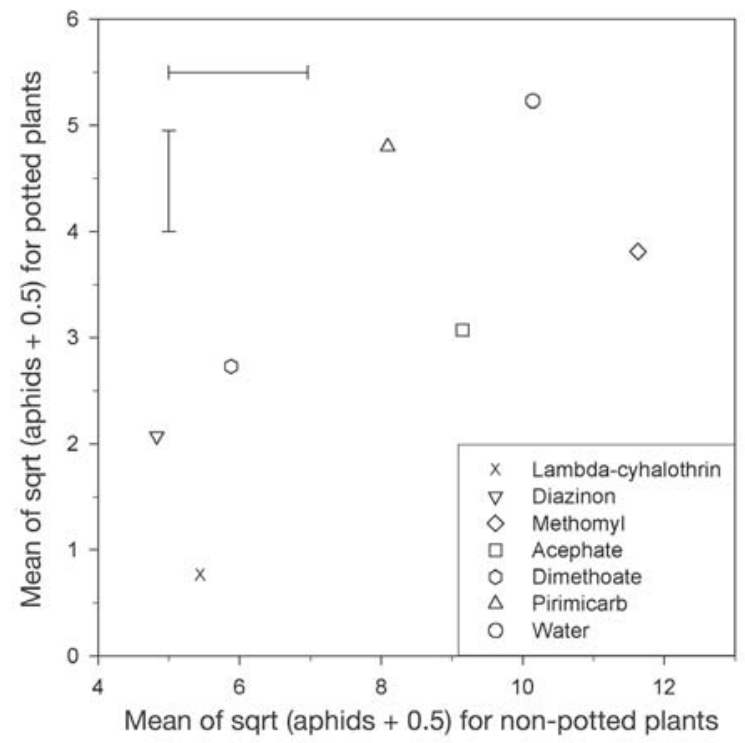

FIGURE 2: Comparison of mean number of aphids per plant from potted and non-potted (destructively sampled) plants 10 days after the second spray (day 21). Raw data were transformed to sqrt(aphids + 0.5), and means are shown on the transformed scale so that precision can be shown. Error bars are LSD $(P<0.05)$ for comparing treatment means for potted and destructively sampled plants respectively. 


\section{DISCUSSION}

A non-linear weighted regression model, which estimated persistence as an initial 'protection period' during which aphid populations were constrained to less than one or two per plant, followed by a linear increase in the number of live aphids present each day, was found to fit the data from both phases of the experiment well.

After a single application of insecticide and continuous pressure imposed by the addition of aphids to replace those killed by the treatments, none of the chemicals except lambda-cyhalothrin provided effective protection, with treatments reaching a population level of five aphids per plant 1-2 days after spraying. Lambda-cyhalothrin reached this level in 4.4 days.

A second spray application 11 days after the first one (with no further live aphids added) provided varying levels of protection. Three chemicals, lambda-cyhalothrin, diazinon and dimethoate, had a persistence period (before aphid populations started to increase) of at least 5 days. The number of days elapsing before populations reached five aphids per plant varied from three to 14 days after the application of the second spray. By this measure, lambda-cyhalothrin, diazinon and dimethoate were the most effective treatments.

The aphid fungal disease Erynia neoaphidis (Roy et al. 2002) was found to have killed some aphids after the second spray application in five of the test plants (about $30 \%$ in two of the water-treated plants and up to $50 \%$ in three of the acephate-treated plants). This may have caused the lower rate of increase in aphid numbers in the acephatetreated plants.

After both spray applications, the acephate and methomyl treatments did not kill all the aphids unlike most of the other insecticides. This confirms what was found in Potter tower tests, where aphids sprayed with acephate and methomyl showed some level of resistance (Workman et al. 2004).

After both spray applications lambda-cyhalothrin offered a higher level of protection, having both a longer persistence period and a significantly lower rate of increase than other chemicals tested. Destructive sampling of non-potted plants in the sprayed plots confirmed that the test procedure, using potted plants and added aphids, gave a precise, informative and realistic comparison of the chemicals being tested.

\section{ACKNOWLEDGEMENTS}

Anton Nikoloff, Seedling Transplants, for the provision of lettuce plants; and MAF Sustainable Farming Fund, Vegfed and other industry sources for funding this work.

\section{REFERENCES}

Barber, M.D.; Moores, G.D.; Tatchell, G.M.; Vice, W.E.; Denholm, I. 1999: Insecticide resistance in the currant-lettuce aphid, Nasonovia ribisnigri (Hemiptera: Aphididae) in the UK. Bull. Entomol. Res.: 89: 17-23.

GenStat 2002. GenStat for Windows, Release 6.2. Sixth edition. VSN International Ltd, Oxford.

Roy, H.E.; Alderson, P.G.; Pell, J.K. 2002: Effect of Erynia neoaphidis and coccinellid foraging on the spatial distribution of aphids on plants. J. Invert. Path.: 81: 127129

Stufkens, M.A.W.; Teulon, D.A.J.; Bulman S.R. 2002: Nasonovia ribisnigri, a new aphid pest found on lettuces (Lactuca sativa L.) and Ribes spp. in Canterbury. N. Z. Plant Prot. 55: 437.

Stufkens, M.A.W.; Teulon, D.A.J. 2003: Distribution, host range and flight pattern of the lettuce aphid in New Zealand. N. Z. Plant Prot. 56: 27.

Workman, P.J.; Stufkens, M.A.W.; Martin, N.A. 2004: Pesticide resistance in lettuce aphid. N. Z. Plant Prot. 57: 239-243. 